\title{
Virtue Ethics: Reflection on and Construction of Moral Education in Colleges*
}

\author{
Jun $\mathrm{Hu}$ \\ School of Marxism \\ Zhejiang University \\ Hangzhou, China 310028
}

\author{
Junru Shen \\ Law School \\ Hangzhou Normal University \\ Hangzhou, China 310028
}

\begin{abstract}
In more recent years, the main moral education mode of colleges takes on 'reason-norm' paradigm, which ensures the ordering development of social morality and the positive impact on moral education of mass students. However, the absolute obligation, generalized rules and ignoring moral agents emerging from that paradigm results on distorting understanding of the values of moral education, moral subjectivity and the moral education functions on moral community. Thus, the timing intervention of virtue ethics can not only connect moral norms and moral agents, but also make up the deficiencies of the paradigm that mentioned above. Specifying goals of moral education based on virtues, launching moral practice adhering to humanism and constructing the feasible paths for moral community cultures will improve moral education system of colleges and seek out new measures for moral practice as well.
\end{abstract} ethics

Keywords—virtue ethics; moral education; colleges; normative

\section{INTRODUCTION}

It is the main purpose of moral education in colleges and universities to cultivate the virtues of young college students so that they can know good, be kind and do good, and then be able to obtain a happy life and benefit the society. However, the current complex external environment and the influence of the Internet society have made the moral development of college students appear a worrying situation, mainly in the diversified moral value conflicts, the inconsistency between individual moral cognition and moral behavior, and the inculcation of a single value. The rejection of the moral education model makes the current effectiveness of college moral education unsatisfactory. How to further reflect and practice what moral subject (college students) should become "moral people", how can colleges and universities better realize "cultivating moral talents". We try to integrate virtue ethics as a value intervention method into the current field of college moral education. By reflecting on the current college moral education system and through the moral education method of virtue ethics intervention, we hope to construct a more perfect and effective modern college moral education

*[Fund Project] This paper has been supported by the Ministry of Education for the demonstration of Marxist colleges and outstanding teaching and research team projects (16JDSZK049), the outstanding talent support program for the young of the Ministry of Education's ideological and political education, the basic business expenses of the central universities and the moral education and students's development center of Zhejiang University. system.

\section{CAlling For ViRTUe: The PRESENT Situation OF MORAL EDUCATION IN COLLEGES AND UNIVERSITIES}

At present, the implementation of moral education in colleges and universities mainly relies on constructing, following and obeying the ethical foundation oriented by specific social systems. It shows that the moral subject follows the principle of rational self-certification, that is, absolute command, revealing the undeniable certainty, the obligations and responsibilities to themselves and others. Morality is the purity of responsibility. The meaning of the survival of moral subjects lies in the obligation, not the fun of life, [1] aiming to train young college students into individuals who know and follow certain political rules and moral rules. The positive effect of this kind of "rational-normative" type of moral education first is the self-discipline generated by obeying moral rules through the establishment of moral norms, developing the most basic rules and moral awareness, and learning to deal with various conflicts in social interaction activities, which are also prerequisites for college students' moral subjects to obtain higher levels of moral quality; Second the "rational-normative" type of moral education provides a practical and normative system of moral education rules for the realization of social order. The orderly moral life cultivated under this system enhances the harmonious coexistence of social interpersonal relationships, and thus promotes the harmony and stability of society as a whole. It is not difficult to see that the biggest characteristic of the "rational-normative" type of moral education model is that it is guided by external ethics and maximizes the function of restricting moral education to the individual. However, it ignores the concern of "human beings" in ethics. After all, the moral norm moral education function needs to be realized through "human". There is still a deficiency in the "rational-normative" moral education work for the nature of moral education, the moral individual subjectivity, and the existence of the "moral community" formed by negotiation (dialogue) and interaction in a specific moral normative situation. These are the current moral education workers in colleges and universities that need to be reflected and resolved.

The value of moral education needs to be fully recognized The "rational-normative" type of moral education believes that the value of morality is the observance of rules by rational individuals. The rules are the mediums that embody moral 
values, and regard college students as "rational people." Under the premise of this kind of "rational person", the knowledge, beliefs and behaviors related to morality are equivalent. Individuals will act according to reason, teaching individuals about moral knowledge, and understanding some of the norms behind the generation of moral behavior, which can make them moral individuals. At present, moral education in colleges and universities relies on the form of knowledge teaching and system education, such as curriculum teaching, school discipline, and reward and punishment regulations, so that students can act based on the principle of moral responsibility, obligation or value maximization. Too much moral value is attached to the moral rules, not the moral subject itself. In a certain sense, the moral subject is neglected for the realization of the "moral of desire". (Human pursuit of happiness, the full realization of human ability is a higher level of moral demand [2]) Failure to fully understand the true value of moral education, and neglect to guide young students to discover and explore the value of moral value - "what kind of person do I want to be?" Moral education has evolved to some extent into a normative education. The goal of education has been to transform college students into moral people into rulers. Or to a large extent, only to achieve a certain political function of moral education - the cultivation of moral education objects into the political power system requires that the excessive instrumental nature of moral education will lead students astray.

It has an insufficient understanding of the subjectivity of moral individuals. The "rational-normative" moral education mode has an unbalanced understanding of the subjectivity and objectivity of college students as moral education objects. One is to over-emphasize the objectivity of the object of education. At present, college moral education focuses on the importance of moral norms in the explicit and implicit level to face the moral cultivation of young students, and focuses on the moral constraints and moral control of moral integration order. Taking the established moral rules as the criterion, it is determined that the individual should become a person who consciously abides by and acts according to the rules. The second is to ignore the understanding of the particularity of the moral individual as a subject. As we all know, the moral subject is not only a mechanical performer of rational responsibility, but also influenced by the subjective characteristics of the educational object (such as quality preference, group culture and other factors). Using rules as a medium of moral value and avoiding the important role of people in realizing moral values will inevitably lead to the separation of morality and humanity. For this reason, this also causes the imbalance of college students as moral subjects in their "self", seeking goodness, inner transcendence, and selfdiscipline. [3] Selfishness, lack of compassion; individual moral cognition is inconsistent with moral behavior; lack of moral self-discipline. The inability to use the correct moral rationality to create correct moral reasoning and judgment in different ethical situations has emerged in the group of college students.

There is not enough emphasis on the education of the moral community. As an important field for constructing college students' moral behavior, colleges and universities should be based on individual students and should be radiated to the whole group of students. At present, the moral education work in colleges and universities has not fully realized the objective existence form of the "moral community" of college students. The moral community itself contains the power of moral education. "If members of the community recognize common goals, care about each other's purposes, and adjust their activities, then they will form a community." [4] The common purpose or pursuit has the function of guiding and regulating the behavior of individuals and groups. The moral community is guided by the same moral concept, and the group members actively participate and cooperate with each other to form a living organism with strong sense of belonging, identity and responsibility in the cultivation of a morally qualified individual for the society. [5] As a form of existence of college students in the moral level, its internal representation mainly has three levels: community, value community and practice community. The relationship community is based on the interactive dimension of interpersonal relationships, which is mainly caused by different hobbies. Its external manifestations are diverse, such as various student organizations, associations, nonprofit organizations, and so on. The value community emphasizes the "moral commitment" between the members of mutual understanding and collective identity and the shared values [6]. The community of practice is to practice ethical behavior under the guidance of certain "common goals or visions". Based on this, the lack of attention paid by colleges and universities to the education of moral community is mainly reflected in the moral education that relies more on moral standards to lead the entire group of college students. However, the understanding of the characteristics of the moral community is not sufficient for the unique lifestyle, emotional needs, moral motives, moral will, and value appeals of the college students. It is impossible to deepen the moral community of college students, find out the commonality, relevance, correctness and applicability, and conceive and practice moral education with the humanistic care, shared culture and common vision required by the "ethnic community".

It can be seen from the above that the moral education workers' understanding of the value orientation of college moral education is more biased towards the understanding of its social value and functional value, while the care of its subject value is still insufficient. How to continue to play the positive role of "rational-normative" moral education work, at the same time, expand the main value of moral education, and make up for the shortcomings of the existing moral education work mode that requires another form of moral education to be integrated into the current moral education of colleges and universities in the form of value intervention.

\section{PURSUING VIRTUE: APPEARANCE OF VIRTUE ETHICS IN COLLEGE MORAL EDUCATION}

At present, moral education in colleges and universities alienates the specific life experiences of young students, ignoring the individual emotions, needs, desires and the care of the unique group culture. It is embodied in the normative system of human nature based on abstract assumptions, and regards "moral rules" or "responsibility" as an end in itself. In 
a sense, the "rational-normative" type of moral education can better accomplish the "reality" part of morality, but it is unable to take into account the moral "sollen" part. The development of the virtues of young students should be the moral meaning that should be pursued in the current moral education of colleges and universities. Since there is some kind of break between norms and people, this requires an intervention based on the "human" moral education model. The timely appearance of virtue ethics can perfect the current college moral education system, or seek another theoretical basis and interpretation model for moral education practice.

The advent of Anscombe's "Modern Moral Philosophy" and MacIntyre's "Following Virtue" marks the revival of virtue ethics, which has aroused the attention and debate of many philosophers. Behind this revival movement has its ancient roots - Aristotle's theory of virtue. Aristotle's theory of sexuality holds that any activity carried out by an individual is based on a certain purpose. "Every practice and choice of man is for a good purpose." [7] The pursuit of human practice is the "happiness" of "getting good or doing well for life" and "the perfect realization of human physical and spiritual activities." [8] "Happiness" is the result of virtue. "Even if happiness is not from God, but through the end of virtue, it must be the best, it must be some kind of sacred well-being." [9] Secondly, Aristotle divides virtue into rational virtue and moral virtue. [10]The former needs to be taught to develop and develop, and the latter needs to be developed through habit. Moral morality is aimed at seeking moderation. The "quality" of virtue is that "the right time, the right place, the right person, the appropriate reason, and the appropriate way to feel these emotions. It is moderate and the best." [11] This requires some kind of practical wisdom (or wise), which essentially means some kind of judgment, that is, to judge a certain "moderate" (medium principle). In this sense, the moral virtues that conform to "quality" can be transformed into certain behavioral abilities. At the same time, moral virtue is also inseparable from the guidance of rationality.

Through the above, in the context of Aristotle's theory of sexuality, it is not difficult to see that virtue has the meaning of function, that is, the "virtue" of an object lies in its functional exertion. The function of nature contained in "virtue" is the natural manifestation of Aristotle's "skopos theory", which also means that moral education cannot ignore human nature or nature, and should pay attention to the cultivation of individual virtue. Morality is based on the individual's call and demand for the intrinsic nature of morality; the main purpose of moral education is not only the cultivation of moral people, but also the cultivation of virtue (perfect). Virtue ethics is based on the overall virtue of the individual, focusing on the formation of individual or group moral character. "Through the excellent moral qualities embodied in the behavioral practice of special human individuals or social groups, it reveals the virtues or moral realms that human beings can achieve as morality or in English." [12] In the view of virtue ethics, virtue plays an important role in the growth of a person. To become a good person is obviously more important than knowing the rules of ethics or moral judgment. The viewpoints of "cultivation of character and virtue" and "symbiosis of practice wisdom and morality" in virtue ethics just find the fulcrum of theory and practice in the current moral education of colleges and universities. The moral education of colleges and universities is manifested in the ethics of virtues, that is, it is to sublimate its work into a moral education that is "soul", conformity, and highlights the intrinsic value of individual life. [13]

It is the need to clarify the goal of moral education. Virtue ethics emphasizes virtue-driven behavior. Moral behavior originates from the actor itself. No matter how the individual's environment changes, the behavior subject can still rely on the virtue drive to implement conscious moral behavior, accompanied by a positive emotional experience. . Virtue is the root of internal order, with moral internality and subjective consciousness of "obligation". In the moral education work of colleges and universities, it is necessary to gradually turn the moral education normative moral education goal into the thinking and practice of the construction of the moral system of the moral subject "what kind of person to become". Every young student needs to achieve self-growth through virtue (such as courage, honesty, self-control, dialectical thinking, generosity, forward-looking, loyalty to justice and fairness, etc.) cultivation. Therefore, the whole society and the country will benefit, and young students should be aware that while pursuing excellence, it is also a process of assisting others to obtain excellence, and finally achieving a state of good life in the whole society. Moral education workers in colleges and universities need to interpret and confirm the virtues of individual internal orientation. It is necessary to clarify the virtues that college students should have.

It is the need to cultivate practical wisdom. Practical wisdom, as a rational side, is closely related to the situation and the things that individuals face in the process of concrete practice. Practical wisdom is a kind of "know how" knowledge that takes advantage of the "rationality" that is designed to guide practitioners how they feel and how to behave in specific situations. In other words, it is the moral subject knows how to initiate the moral judgment that adapts to the situation according to the specific situation. It is a situationalized ability that contains empirical components. [14] Therefore, the cultivation of students' moral judgment and value sorting ability is one of the factors that cannot be ignored when setting up moral education activities in college moral education. Individuals have good moral judgment and choice ability. Thanks to the rationality of thinking about the past, the extent of past experience and events related to emotions, and the extent to which successes and failures have been reflected. Practical wisdom requires the ability to be sensitive to the environment, knowing when, how and by what strategy, which requires college moral education workers to know how to match specific situations with virtue types.

At the same time, practical wisdom requires understanding and recognizing the importance of experience integrated into a particular situation. Good judgment depends on the depth of experience accumulated by the individual. Experience accumulates depends on time, and experience is lacking for young people. Undoubtedly, it is more difficult for young students with lesser experience to gain practical wisdom. This requires that college moral education work should ensure that college students can reach the initial level of practical wisdom before they enter society, helping them avoid too many 
mistakes, and with the accumulation of experience, let them become individuals who can truly use practical wisdom. In this process, college moral education workers should focus on the campus in their specific work, but also focus on the society, and connect and integrate local and overall life experiences to help young students gain practical wisdom.

It is the need for the construction of a moral community. "Into a practice is to integrate not only with the current practitioners, but also with those who enter this practice earlier than us.... Virtue is maintained existing relationship in practice in the same way and the same reason."[15] The ability of individuals to engage in ethical behavior depends on their growth environment, their education, and the opportunities, education, good role models, or interpersonal social networks they face in character development. In other words, virtue points to the integrity of individual life, rather than the individual behavior, and the development of individual virtues is in the moral community in which they live. The moral community is formed on the basis of common moral will, emotion, belief, etc. Therefore, the activity of forming virtue is the practice of interpersonal cooperation in the moral community. The category of individual virtues is social, that is, it is in the living environment, when individuals share moral goals, the behavior of virtues applied to others can enhance and enrich social relations and others' lives. It is true that there will also be conflicts among members of the moral community. The process of community division of differences and compromises between members is also a process of moral education. As a carrier of moral value formation and practice, the moral community has an indispensable educational power, and its "peer education" form is a powerful way to improve the effectiveness of moral education.

\section{ACQUIRING VIRTUE: THE REALIZATION OF VIRTUE ETHICS IN COLLEGE MORAL EDUCATION}

The development of anything is goal-oriented in the sense of virtue and ethics. Any behavior and choice is to achieve a certain purpose, and this purpose is virtue. Under the guidance of the purpose of realizing virtue, Aristotle's virtue theory regards moral life as a practical field of human inquiry and its behavioral expression. Practice methods such as training and habituation play an important role. At the same time, proper emotional cultivation is a vital part of the development of virtues in relation to the sensitivity of the situation. The path of learning virtue depends more on the specific natural human ability and the cultivation and improvement of the sensibility of oneself and others. On the list, the role model plays an important role. Moreover, the long-standing ethics of the United States regards the humanistic literary heritage full of "narrative nature" as an important factor influencing individual moral sensibility and forming individual cultural moral identity. From the above, the clear goal of moral education, the moral practice of tempering people, the moral community in which individuals are built, and their moral environment are important paths for the realization of virtue.

Embody the goal of moral education. In the process of confirming the purpose of morality, college moral education workers need to examine the virtues that contemporary college students already possess from the perspective of "student- school-society". Although the German system itself has an universality, it does not mean that its application path and specific environment are consistent. The environment is different, and the content and form of the German system based on specific situations are appropriate. The social environment in which virtues can be practiced is the decisive factor in the form and content of Germans. That is to say, the setting of moral education goals in colleges and universities should meet the basic needs of the students while catering to their own development needs. At present, the setting of college moral education goals should consider the four core values of "patriotism, dedication, honesty and friendliness" mentioned in the social behavior core values. Realizing the value leadership of college students, it also points out long-term strategic goals for college moral education. Of course, we must learn to choose the content of moral education suitable for the university students from the Western virtues and the system of morality, and we cannot completely abandon the essence of the thoughts on the division of morality contained in traditional Chinese Confucianism.

With regard to the construction and improvement of the virtues and virtues, foreign scholars have made corresponding explorations. For example, the four core virtues (wisdom, courage, self-restraint and justice), the six virtues (wisdom, courage, benevolence, justice, moderation and transcendence) and the 24 good qualities refined on this basis (ie "action good value classification system", referred to as VIA-IS) [16]. On the basis of the research results of the virtues and virtues in ancient and modern China and abroad, some scholars in China have proposed sixteen virtues based on four logical sections. That is, individual virtues (including self-love, wise, selfcontrol, moderate), interpersonal virtues (filial piety, friendship, equality, responsibility), civic virtues (reporting the country, honour, dedication, protecting the environment) and social virtues (integrity, harmony, justice, dedication). [17]When establishing the system of morality, we must use the perspective of virtue to develop and realize it, rather than just staying on the exploration of its normative meaning.

Carry out the "people-oriented" moral practice. For the virtues based on connection, uninterrupted practice, in order to strengthen and implement the script in virtue, is the best solution for shaping virtue. It is a time-consuming and laborious process. [18] Virtue ethics explores and embodies various virtues, clarifies the dependence of character on the environment, and emphasizes the importance of "practical wisdom" for the development of character and morality. The educational function of moral education in colleges and universities is embodied in its informal educational role, especially in encouraging young students to become people with good habits, decent minds, and Walk the Talk. The main path of moral education in colleges and universities - learning adults and educating people in practice should conform to the concept of "specific practice itself". That is to say, for shaping social students to become social citizens with good moral character, while moral education in colleges and universities pays attention to moral knowledge training, the most important thing is to implement moral character education from the "life itself" of young students. Let students walk out of the classroom, get out of the campus, integrate into society and life, 
and the ultimate goal of thinking to lead and promote young students is to change their personality and nature. Virtue can be learned, good character is the product of good moral education, as Aristotle said, "All virtues that nature and nature give us are different, we use it before we get them."

The ability of young students to transform the world, the ability to acquire social goodness, and the ability to exert influence on the social environment are all derived from the "human subjectivity" or "self-determination" contained in college moral education. By this characteristic, colleges and universities have the obligation and responsibility to provide a diversified approach for college students' moral practice, so that they can face moral situations, feel moral emotions, grasp complex moral relationships, make reasonable moral judgments, and form corresponding moral behaviors. Here, the moral practice provided by colleges and universities should follow the principle of "student". Moral practice should be derived from the needs of students' own moral cultivation, rather than merely satisfying political needs and flowing in form. Moral education workers in colleges and universities should try to embed the moral education work into the moral life of students and make full use of the real and perceptible moral education resources around them.

Build a cultural environment of a moral community. How to build a moral community in colleges and universities, and to infiltrate moral education into the moral community, the key is to create a campus culture on which the moral community is based. Through the construction of the campus cultural environment, we strive to create an environment conducive to the cultivation of young students' character and virtue. Specifically, the first is to highlight the value sharing of moral culture in colleges and universities. The values and ethics clearly defined by colleges and universities should be recognized and shared by all teachers and students, so that they can gather strengths and struggle for common goals. Second, we must create a sense of humanistic care in college culture. As students feel the love between people, the students will treat the other members of the community in the same way, and form the corresponding virtues invisibly. The third is to form the common participation of university culture. As a whole moral community, the school should also incorporate the teacher's moral community while paying attention to the moral community of college students. It should influence the formation of students' good morality with the teacher's morality, and should also increase the participation of young students in the management of school affairs. Since the process of deliberative democracy will promote the development of young students' virtues and social goodness, the moral culture construction of colleges and universities should vigorously guide students to obtain the consistency of the form and content of virtues in the way of participating in deliberative democratic practice activities. The fourth is to integrate traditional virtue education. Virtue ethics focuses on historical narratives, obsessed with the cultural traditions of the community and its derivatives. Historical narratives are actually "telling stories" [19]. Traditional virtue education is a link between the past and the present for college students. Young students who are in the era of diversified values can easily lose themselves in morality. As a generation of generations, the traditional virtues of morality and practice can give historical guidance to the moral behavior of college students.

The thinking about the implementation path of the virtue theory of college moral education is not because of the long history of virtue ethics. It is the virtue ethics that reflects some of the natural views on moral development. To a greater extent, it is a loyalty to moral growth and the common sense of education, and a true description of the complexity of moral life. Only returning moral education to the maintaining and explorations of human virtues and moral meanings, it is possible to truly highlight the subjectivity of people in the process of moral education in colleges and universities and better realize the fundamental goal of "cultivating people with morality" in colleges and universities.

\section{CONCLUSION}

The thinking about the implementation path of the virtue theory of college moral education is not because of the long history of virtue ethics. It is the virtue ethics that reflects some of the natural views on moral development. To a greater extent, it is a loyalty to moral growth and the common sense of education, and a true description of the complexity of moral life. Only returning moral education to the maintaining and explorations of human virtues and moral meanings, it is possible to truly highlight the subjectivity of people in the process of moral education in colleges and universities and better realize the fundamental goal of "cultivating people with morality" in colleges and universities.

\section{REFERENCES}

[1] Kant. Practical Rational Critique [M], translated by Deng Xiaomang. Beijing: People's Publishing House, 2003: 120

[2] Fowler. The morality of law [M], translated by Zheng Ge. Beijing: The Commercial Press, 2005: 6

[3] Feng Jianjun. Human Moral Subjectivity and Subject Moral Education[J].Journal of Nanjing Normal University(Social Science Edition),2002(2):84

[4] Dewey. Democracy and Education [M], translated by Wang Chengxu. Beijing: The Commercial Press, 1990: 6

[5] Kong Fanjian. Discussion on the Construction and Trend of Moral Education Community [D], China University of Mining and Technology, 2015

[6] Song Ye, Gu Yuling. Moral Community: The Core Pursuit of School Moral Culture Construction[J]. Journal of Inner Mongolia Normal University (Science Edition), 2013(10): 22

[7] Aristotle. The Nicomachean Ethics [M], translated by Liao Shenbai Translation. Beijing: The Commercial Press, 2003: 1

[8] Aristotle. The Nicomachean Ethics [M], translated by Liao Shenbai Translation. Beijing: The Commercial Press, 2003: 7

[9] Aristotle.The Nicomachean Ethics [M], translated by Liao Shenbai Translation. Beijing: The Commercial Press, 2003: 25

[10] Aristotle. The Nicomachean Ethics[M], translated by Liao Shenbai Translation. Beijing: The Commercial Press, 2003: 36

[11] Aristotle. The Nicomachean Ethics[M], translated by Liao Shenbai Translation. Beijing: The Commercial Press, 2003: 49

[12] Wan Junren. Several Theoretical Issues on the Study of Virtue Ethics[J]. Moral and Civilization, 2008(3):17

[13] Fang Dezhi. Virtue Rejuvenation and Moral Education - On the Revelation of Aristotle's Moral Theory to the Renaissance of Virtue Ethics[J].Ethics Research,2010(3):63-68 
[14] Julia Annas. Applying Virtue to Ethics [J]. Journal of Applied Philosophy, 2015 (32): 1-14

[15] Wang Hongbo, Li Ying. The Moral Outlook of Communitarianism[J]. Journal of Nantong University (Social Science Edition), 2008(1): 46

[16] Peterson,C.,Seligman, M. E. P. Character Strengths and Virtues: A Handbook and Classification[M]. New York: Oxford University Press Washington, 2004:35-40

[17] Xiao Qunzhong. The Interpretation of Virtue and the Study of Virtue Ethics[J]. Journal of Guangxi University for Nationalities(Philosophy and Social Sciences), 2006(5): 125-126

[18] Yu Feng et al. Social and Personality Psychology Analysis of Ethical Virtue: Significance, Confusion and Analysis of Moral Traits[J]. Journal of Tsinghua University (Philosophy and Social Sciences), 2012(4): 139

[19] Wan Junren. Several Theoretical Issues on the Study of Virtue Ethics[J]. Morality and Civilization, 2008(3): 20. 